\title{
EXPERIMENTAL AND THEORETICAL CHARACTERIZATION OF THICK AND THIN FILMS FOR MICROWAVE USES ON 99.6\% ALUMINA SUBSTRATES
}

\author{
J.P. RAMY, R. SCHNITZLER and C. THEBAULT \\ Centre National d'Etudes des Télécommunications, B.P. 40, 22301 Lannion Cedex, France
}

(Received October 3 1981; in final form November 2 1981)

In a previous paper, ${ }^{1}$ we showed, with a microwave quality factor (Q) measurement, that in the $X$ band and with alumina substrates, thick film losses are not worse than thin film losses when the inks are screened then etched, and when they have copper oxide as adhesive layer and gold or copper as metal powder.

Here, we extend this study to show that, our experimental results being in good agreement with theory, a simple D.C. resistivity measurement is sufficient to characterize these MIC'S metallizations and is as suitable as a microwave $\mathrm{Q}$ measurement. We also show that the nature of the ground plane cannot be neglected.

\section{INTRODUCTION}

A large part of MIC technology is concerned with materials: the properties of metallizations, as well as substrates, are of particular importance.

The classical method used to characterize these metallizations is to determine their losses by a microwave quality factor (Q) measurement. This method is relatively complex and tedious, so we have worked out an easier method which gives good agreement with the theory.

\section{CHARACTERIZATION METHODS}

As we give some formulas in this section, we define here the symbols which will be used.

$\lambda_{g}, \lambda_{0}:$ guided and free space wavelength $Q:$ unloaded quality factor

F, C: $\quad$ frequency and light velocity $\quad \alpha_{0}$ : free space losses

$\epsilon: \quad$ substrate dielectric constant $\quad \alpha_{\mathrm{D}}: \quad$ dielectric substrate losses

$\epsilon_{\text {eff }}: \quad$ substrate effective dielectric $\quad \alpha_{\mathrm{G}}, \alpha_{\mathrm{L}}:$ ground plane and line losses constant

$\operatorname{Tan} \delta: \quad$ substrate loss tangent

$R_{G}, R_{L}:$ ground plane and line skin resistance

$\mu_{0}, \epsilon_{0}:$ free space permeability and $\quad \rho_{\mathrm{G}}, \rho_{\mathrm{L}}:$ ground plane and line resistivity permittivity

$\mathrm{q}$ : dielectric filling factor w, width and thickness line

$\mathrm{Z}_{0}$ : free space impedance $\mathrm{h}$ : dielectric substrate thickness

2.1 Classical characterization method. The design of MIC's requires the measurements of losses by the mean of an unloaded $Q^{\prime}$ measurement. This method has been described 
in an earlier paper. ${ }^{1} \mathrm{Q}$ is related to the losses by the following equation:

$$
\mathrm{Q}=\pi / \alpha \cdot \lambda_{\mathrm{g}}
$$

with

$$
\lambda_{\mathrm{g}}=\lambda_{0} /\left(\epsilon_{\mathrm{eff}}\right)^{1 / 2}=\mathrm{C} / \mathrm{F}_{0}\left(\epsilon_{\mathrm{eff}}\right)^{1 / 2}
$$

This method is complex (requiring sophisticated equipment) and tedious (it requires a photo etching of the pattern, ${ }^{1}$ and we have instabilities during the measurements at high frequencies).

\subsection{An easier characterization method.}

Because of the disadvantages of the microwave $Q^{\prime}$ measurements, we have developed an easier method which is based upon a D.C. resistivity measurement.

2.2 a. Theory. The losses in MIC'S are generally divided into two parts: 1) the dielectric losses, and 2) the ohmic losses, which are themselves divided in two parts: the ground plane and line losses.

2.2.a.1. Dielectric losses: $\alpha_{D}$. As formulated by PUCEL, ${ }^{2}$ we can define $\alpha_{D}$ as:

$$
\alpha_{\mathrm{D}}=27.3\left(\mathrm{q} \epsilon / \epsilon_{\mathrm{e}}\right) \tan \delta / \lambda_{\mathrm{g}} \mathrm{db} / \mathrm{cm}
$$

with $\epsilon_{\mathrm{e}}=1+\mathrm{q}(\epsilon-1)$, $\mathrm{q}$ being the dielectric filling factor defined by WHEELER. ${ }^{3}$

2.2.a.2. Ohmic losses: $\alpha_{G}+\alpha_{L} \cdot \alpha_{G}$ can be written as:

$$
\begin{gathered}
\alpha_{\mathrm{G}}=\alpha_{0}\left(\epsilon_{\mathrm{eff}}\right)^{1 / 2} \\
=>\alpha_{\mathrm{G}}=\left(\epsilon_{0} \epsilon_{\mathrm{eff}} / \mu_{0}\right)^{1 / 2}\left(\mathrm{R}_{\mathrm{G}} / 2 \mathrm{Z}_{0}\right) \partial \mathrm{Z}_{0} / \partial \mathrm{h}
\end{gathered}
$$

with

$$
\mathrm{R}_{\mathrm{G}}=\left(\pi \cdot \mu_{0} \cdot \mathrm{F} \cdot \rho_{\mathrm{G}}\right)^{1 / 2}
$$

The partial derivative $\partial \mathrm{Z}_{0} / \partial \mathrm{h}$, valid for $\mathrm{w} / \mathrm{h} \leqslant 1$, is given by SCHNEIDER, ${ }^{4}$ :

$$
\partial \mathrm{Z}_{0} / \partial \mathrm{h}=-\left(\mathrm{W} / \mathrm{h}^{2}\right) \partial \mathrm{Z}_{0} / \partial(\mathrm{w} / \mathrm{h})
$$

We have, ${ }^{4}$ :

$$
Z_{0}=60 \operatorname{Ln}(8 \mathrm{~h} / w+w / 4 h)
$$

so,

$$
\partial Z_{0} / \partial(w / h)=60\left(2 w / h /\left[32+(w / h)^{2}\right]-h / w\right)
$$

and we obtain: 
$\alpha_{\mathrm{G}}=-30 \frac{\left(\pi \cdot \epsilon_{0} \cdot \mathrm{F} \cdot \epsilon_{\mathrm{eff}} \cdot \rho_{\mathrm{G}}\right)^{1 / 2}}{\mathrm{Z}_{0}}\left(\frac{2 \mathrm{w}^{2} / \mathrm{h}_{3}}{32+(\mathrm{w} / \mathrm{h})^{2}}-1 / \mathrm{h}\right)$

Similarly, we can formulate $\alpha_{\mathrm{L}}$ as:

$\alpha_{\mathrm{L}}=\left(\epsilon_{0} \cdot \epsilon_{\mathrm{eff}} / \mu_{0}\right)^{1 / 2}\left(\mathrm{RL} / 2 \mathrm{Z}_{0}\right)\left(\partial \mathrm{Z}_{0} / \partial \mathrm{h}-2 \partial \mathrm{Z}_{0} / \partial \mathrm{w}-2 \partial \mathrm{Z}_{0} / \partial \mathrm{t}\right)$

with

$$
\mathrm{R}_{\mathrm{L}}=\left(\pi \cdot \mu_{0} \cdot \mathrm{F} \cdot \rho_{\mathrm{L}}\right)^{1 / 2}
$$

The partial derivatives can be formulated as:

$$
\partial Z_{0} / \partial w=(1 / h) \partial Z_{0} / \partial(w / h)
$$

and

$$
\partial \mathrm{Z}_{0} / \partial \mathrm{t}=\left(\partial \mathrm{Z}_{0} / \partial \mathrm{w}\right)(\partial \mathrm{w} / \partial \mathrm{t})=(1 / \mathrm{h})\left(\partial \mathrm{Z}_{0} / \partial(\mathrm{w} / \mathrm{h})\right)(1 / \pi) \operatorname{Ln}(2 \mathrm{~h} / \mathrm{t})
$$

for $w / h \geqslant 1 / 2 \pi .^{4}$ Arranging [11], [12], [13] , [14] and [7], we have:

$$
\alpha_{L}=-30 \frac{\left(\pi \cdot \epsilon_{0} \cdot \mathrm{F} \cdot \epsilon_{\text {eff }} \cdot \rho_{\mathrm{L}}\right)^{1 / 2}}{\mathrm{Z}_{0}}\left(\frac{2 \mathrm{w} / \mathrm{h}}{32+(\mathrm{w} / \mathrm{h})^{2}}-\mathrm{h} / \mathrm{w}\right)\left[\mathrm{w} / \mathrm{h}^{2}+2 / \mathrm{h}+(2 / \mathrm{h} \pi) \operatorname{Ln}(2 \mathrm{~h} / \mathrm{t})\right]
$$

2.2.b. Theoretical and experimental results. To compare with experimental results at $10 \mathrm{GHz}$, we take a microstrip line $0.0635 \mathrm{~cm}$ width and $0.001 \mathrm{~cm}$ thick; the substrate is $0.0635 \mathrm{~cm}$ thick. With $\alpha$ in Np/cm, F in Hertz, $\rho_{\mathrm{L}}$ and $\rho_{\mathrm{G}}$ in $\Omega . \mathrm{cm}, \mathrm{w}, \mathrm{h}$ and $\mathrm{t}$ in $\mathrm{cm}$, $\epsilon_{0}=8.85 .10^{-14} \mathrm{Farad} / \mathrm{cm}, \epsilon_{\text {eff }}=6.8$ and $\mathrm{C}=3.10^{10} \mathrm{~cm} / \mathrm{s}$, we have theoretically: $\mathrm{Q}=2.73 /\left(\alpha_{\mathrm{G}}+\alpha_{\mathrm{L}}\right)$ from equation $[1] ; \mathrm{Z}_{0}=126.6 \Omega$ from equation [8]; $\alpha_{\mathrm{G}}=0.482$ $\left(\rho_{\mathrm{G}}\right)^{1 / 2}$ from equation [10]; $\alpha_{\mathrm{L}}=2.933\left(\rho_{\mathrm{L}}\right)^{1 / 2}$ from equation [15]. Theoretical ohmic losses, measured and theoretical $Q$, are computed in table 1 and plotted in figure 1 , for the resistivities of the thick and thin films used.

\section{DISCUSSION}

From equations [10] and [15], tables I and II, and figure 1, it can be seen theoretically and experimentally that: 1) the losses are dependent upon the resistivity, and 2) the ground plane resistivity cannot be neglected.

\subsection{Evaluation and characterization of MIC'S by a resistivity measurement.}

It is of great interest to know if this simple method permits not only a comparison between different metallizations (evaluation), but also constitutes a characterization method, and consequently a means of determining the absolute value of losses, such as the $Q$ measurement.

We have seen that, with figure 1 , we give the theoretical and experimental curves $\mathrm{Q}=\mathrm{f}(\rho)$. If we take into account the only ohmic losses (table I), we can see that there is a divergence between theoretical and experimental $Q$; this difference increases when the resistivity decreases. 


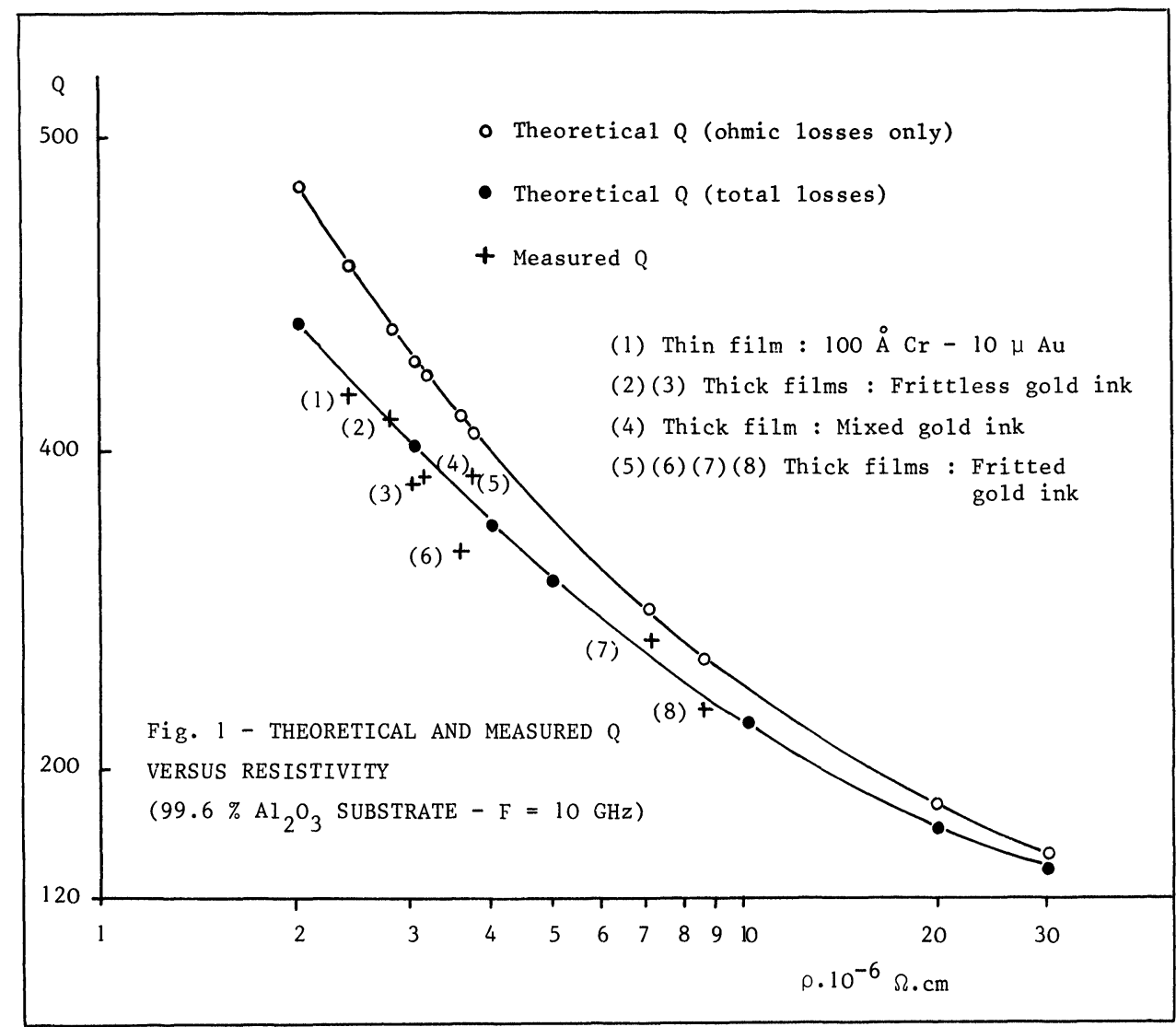

TABLE I

Theoretical ohmic losses, measured and theoretical $\mathrm{Q}$ for thick and thin films used

\begin{tabular}{|c|c|c|c|c|c|}
\hline \multirow[t]{2}{*}{$\begin{array}{l}\text { Pattern } \\
\text { technology }\end{array}$} & \multirow[t]{2}{*}{$\begin{array}{l}\text { Measured } \rho \\
10^{-6} \Omega . \mathrm{cm}\end{array}$} & \multicolumn{2}{|c|}{$\begin{array}{c}\text { Theoretical ohmic } \\
\text { losses } \\
10^{-3} \mathrm{~Np} / \mathrm{cm}\end{array}$} & \multirow{2}{*}{$\begin{array}{l}\text { Theoretical } \\
Q \\
F=10 \mathrm{GHz}\end{array}$} & \multirow{2}{*}{$\begin{array}{l}\text { Measured } \\
Q \\
F=10 \mathrm{GHz}\end{array}$} \\
\hline & & $\alpha_{\mathbf{G}}$ & $\alpha_{L}$ & & \\
\hline Thin film & 2.4 & 0.747 & 4.544 & 516 & 436 \\
\hline $\begin{array}{l}\text { Thick film } \\
\text { (etched pattern) }\end{array}$ & $\begin{array}{l}2.79 \\
3.05 \\
3.15 \\
3.6 \\
3.75 \\
7.1 \\
8.74\end{array}$ & $\begin{array}{l}0.805 \\
0.842 \\
0.855 \\
0.915 \\
0.933 \\
1.284 \\
1.425\end{array}$ & $\begin{array}{l}4.899 \\
5.122 \\
5.206 \\
5.565 \\
5.680 \\
7.815 \\
8.671\end{array}$ & $\begin{array}{l}479 \\
458 \\
450 \\
421 \\
413 \\
300 \\
270\end{array}$ & $\begin{array}{l}419 \\
380 \\
384 \\
338 \\
385 \\
281 \\
237\end{array}$ \\
\hline
\end{tabular}

The influence of the ground plane resistivity on the measured and theoretical $Q$ is displayed in table II. 
TABLE II

Ground plane resistivity influence on measured and theoretical Q. The line pattern is etched;2.79. $10^{-6} \Omega . \mathrm{cm}$ is a frittless gold ink resistivity; $32.4 .10^{-6} \Omega . \mathrm{cm}$ is a fritted silver-palladium ink resistivity

\begin{tabular}{|c|c|c|c|c|c|}
\hline \multirow{2}{*}{$\begin{array}{l}\text { Measured } \rho \\
\begin{array}{l}\text { Ground } \\
\text { plane }\end{array}\end{array}$} & \multirow{2}{*}{$\frac{10^{-6} \Omega . \mathrm{cm}}{\text { Line }}$} & \multicolumn{2}{|c|}{$\begin{array}{c}\text { Theoretical ohmic } \\
\text { losses } \\
10^{-3} \mathrm{~Np} / \mathrm{cm}\end{array}$} & \multirow{2}{*}{$\begin{array}{l}\text { Theoretical } \\
Q \\
F=10 \mathrm{GHz}\end{array}$} & \multirow{2}{*}{$\begin{array}{l}\text { Measured } \\
\mathrm{Q} \\
\mathrm{F}=10 \mathrm{GHz}\end{array}$} \\
\hline & & $\alpha_{G}$ & $\alpha_{\mathbf{L}}$ & & \\
\hline 2.79 & 2.79 & 0.805 & 4.899 & 479 & 419 \\
\hline 32.4 & 2.79 & 2.744 & 4.899 & 357 & 354 \\
\hline
\end{tabular}

To obtain a good agreement, we must introduce the dielectric losses $\alpha_{\mathrm{D}}$, and a correcting factor $\mathrm{K}$ which takes into account the surface roughness of the substrate. At $10 \mathrm{GHz}$, with $\tan \delta=2.10^{-4}$, and $\mathrm{q} \epsilon / \epsilon \mathrm{e} \simeq 0.9375,{ }^{2}$ we have: $\alpha_{\mathrm{D}}=0.513 .10^{-3} \mathrm{~Np} / \mathrm{cm}$ from equation [3], and $\mathrm{K} \simeq 1.05$. $^{5}$

The table III presents the total theoretical losses $\left(\alpha_{D}, \alpha_{G}, \alpha_{L}\right.$, and surface roughness losses) and $\mathrm{Q}$ for different resistivities.

From table III, we can see that the dielectric losses cannot be neglected for the lower resistivities, but the greater the resistivity is, the more $\alpha_{D}$ can be neglected. This explains the divergence between theoretical (if only computed with ohmic losses) and experimental $Q$ (see figure 1).

If we take into account the total losses, we can see from figure 1 , that there is a very good agreement between theory and practice, and that consequently the resistivity measurement is a characterization method of MIC's as suitable as the Q measurement.

\subsection{Influence of the ground plane.}

For a lower cost, it would be attractive to use a ground plane metallization such as silverpalladium which is about ten to fifteen times less expensive than gold. Unfortunately, the results show that the ohmic losses are very much higher than when we have gold as ground plane and conductor line. So, if we compute $\alpha_{G}$ versus $\alpha_{L}$ with equations [10] and [15] for the experimental resistivities used (see table II), we have $\alpha_{G} \simeq 0.16 \alpha_{L}$ for a $2.79 \mu \Omega$.cm frittless gold conductor line and ground plane, and $\alpha_{\mathrm{G}} \simeq 0.56 \alpha_{\mathrm{L}}$ when the gold ground plane is substituted by silver-palladium. As we can see in table IV, we have a good agreement between theory and measurements if we take into account the total losses $\left(\alpha_{D}, \alpha_{G}, \alpha_{L}\right.$ and surface roughness losses).

TABLE III

Total theoretical losses and $\mathrm{Q}$ for some resistivities

\begin{tabular}{|c|c|c|c|c|c|}
\hline $10^{-6} \Omega . \mathrm{cm}$ & $10^{-3} \mathrm{~Np} / \alpha_{\mathrm{D}}$ & $10^{-3} \stackrel{\alpha_{G}}{\mathrm{~Np} / \mathrm{cm}}$ & $\begin{array}{c}\alpha_{\mathrm{L}} \\
10^{-3} \mathrm{~Np} / \mathrm{cm}\end{array}$ & $\begin{array}{l}\text { Total losses } \\
10^{-3} \mathrm{~Np} / \mathrm{cm} \\
K\left(\alpha_{D^{+}} \alpha_{G}+\alpha_{L}\right)\end{array}$ & $\begin{array}{l}\text { Theoretical } \\
Q \\
F=10 \mathrm{GHz}\end{array}$ \\
\hline $\begin{array}{r}2 \\
3 \\
4 \\
5 \\
5 \\
10 \\
20 \\
30\end{array}$ & $\begin{array}{l}0.513 \\
0.513 \\
0.513 \\
0.513 \\
0.513 \\
0.513 \\
0.513\end{array}$ & $\begin{array}{l}0.682 \\
0.835 \\
0.964 \\
1.078 \\
1.524 \\
2.156 \\
2.640\end{array}$ & $\begin{array}{r}4.148 \\
5.080 \\
5.866 \\
6.558 \\
9.275 \\
13.117 \\
16.065\end{array}$ & $\begin{array}{r}5.610 \\
6.749 \\
7.710 \\
8.556 \\
11.878 \\
16.575 \\
20.179\end{array}$ & $\begin{array}{l}487 \\
404 \\
354 \\
319 \\
230 \\
165 \\
135\end{array}$ \\
\hline
\end{tabular}


TABLE IV

Theoretical and experimental effect of ground plane metallization on Q. For $\alpha_{D}, \alpha_{G}$ and $\alpha_{L}$ values, see tables II and III; $\mathrm{K}=1.05 .^{\mathrm{s}}$

\begin{tabular}{|c|c|c|c|}
\hline \multicolumn{2}{|l|}{$\rho 10^{-6} \Omega . \mathrm{cm}$} & \multirow{2}{*}{$\begin{aligned} & \text { Theoretical } Q \\
Q= & 2.73 / K\left(\alpha_{D}+\alpha_{G}+\alpha_{L}\right) \\
F= & 10 \mathrm{GHz}\end{aligned}$} & \multirow{2}{*}{$\begin{array}{l}\text { Measured } Q \\
F=10 \mathrm{GHz}\end{array}$} \\
\hline Ground plane & Line & & \\
\hline 2.79 & 2.79 & 418 & 419 \\
\hline 32.4 & 2.79 & 318 & 354 \\
\hline
\end{tabular}

\section{CONCLUSION}

Because we have a good agreement between theory and practice, we have shown that a simple D.C. resistivity measurment is as suitable as a more complex microwave $\mathbf{Q}^{\prime}$ measurement, in order to characterize the MIC'S metallizations.

We have also showed that the nature of the ground plane cannot be neglected.

\section{ACKNOWLEDGEMENTS}

The authors are indebted to B. Loriou for his invaluable assistance in performing this study.

\section{REFERENCES}

1. J.P. Ramy et al., IEEE Trans. Mtt. MTT 26, no 10. pp. 814-820 (October 1978).

2. R.A. Pucel. et al., IEEE Trans Mtt. MTT 16, no 6. pp. 342-350, (June 1968).

3. H.A. Wheeler, IEEE Trans Mtt. MTT 13, pp. 172-185, (March 1965).

4. H.V. Schneider, Bell System Technical Journal. pp. 1421-1444, (May-June 1969).

5. H. Sobol, Proceedings IEEE Fall Electronics Conference, October 1971. 

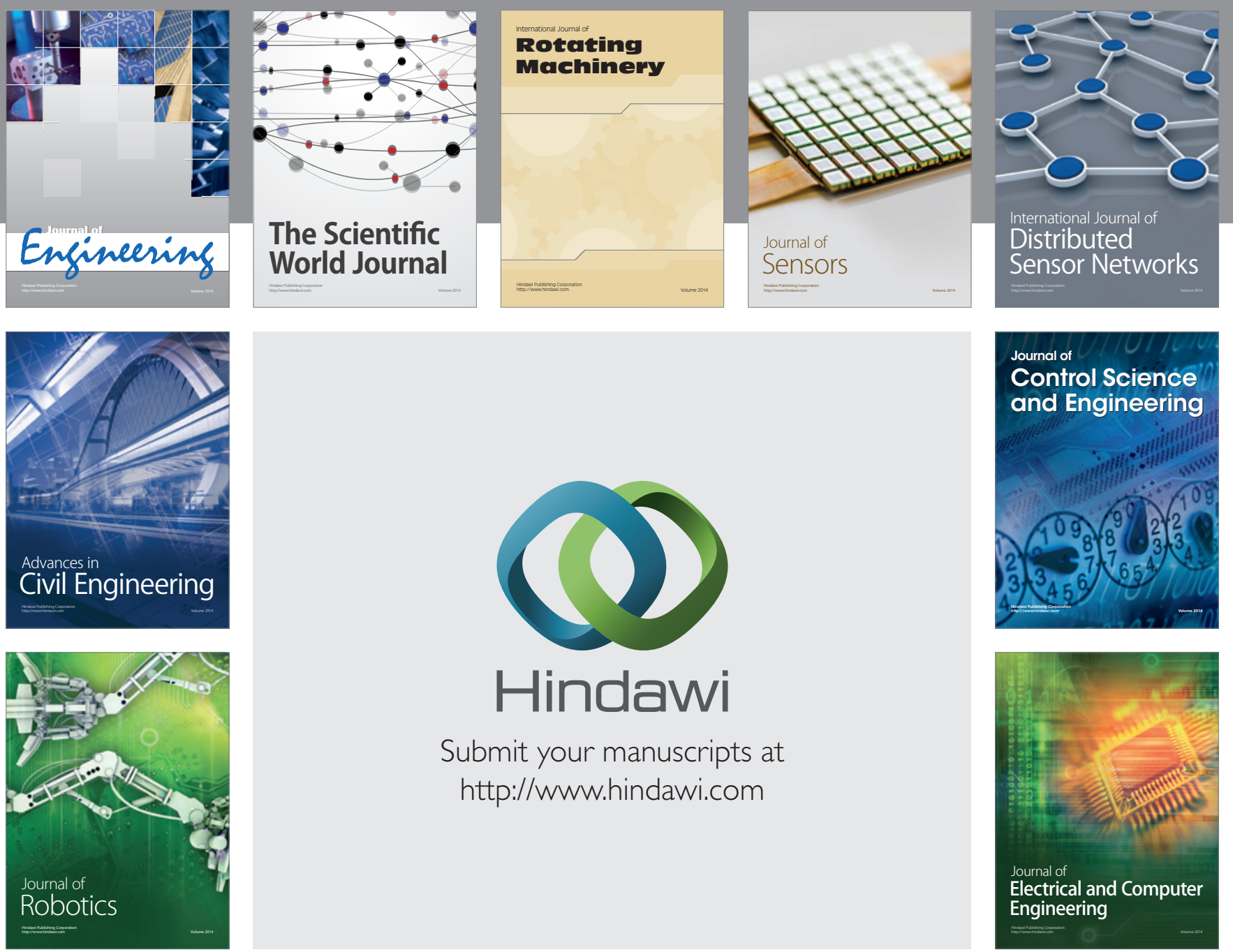

Submit your manuscripts at

http://www.hindawi.com
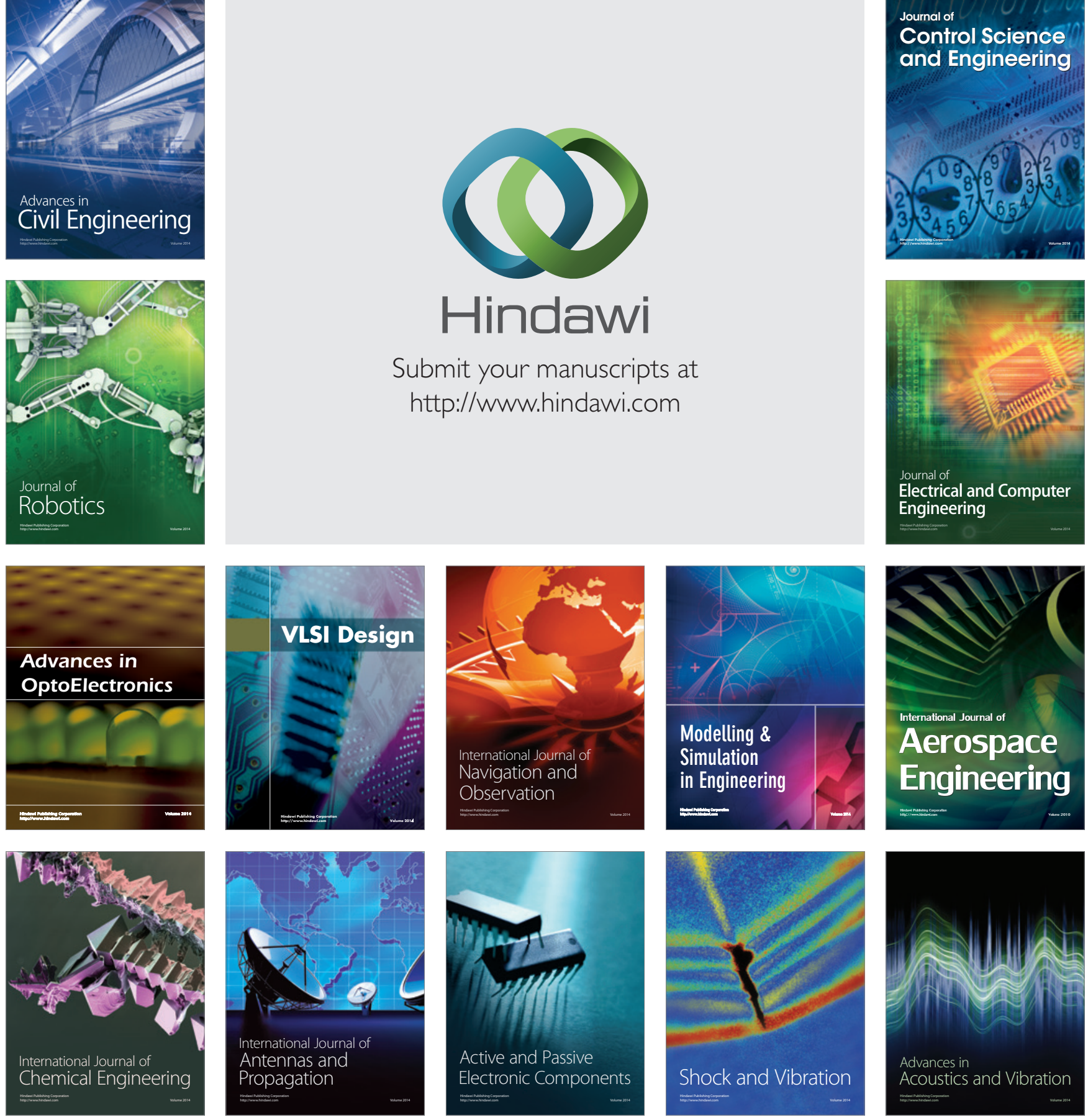